\title{
Ruido y quietud en el interior de los parques de Madrid (España): Un análisis ambiental de casos con SIG
}

\author{
Pedro MARTínez SUÁREZ \\ Dpto. de Geografía. Universidad Autónoma de Madrid \\ pedro.suarez@uam.es \\ Antonio MORENO JIMÉNEZ \\ Dpto. de Geografía. Universidad Autónoma de Madrid \\ antonio.moreno@uam.es
}

Recibido: 22 de enero de 2013

Enviado a evaluar: 22 de marzo de 2013

Aceptado: 14 de mayo de 2013

\section{RESUMEN}

Este trabajo aborda el estudio del ruido ambiental en el seno de los parques de la ciudad de Madrid, los cuales deberían constituirse como espacios de descanso y sosiego dentro del dosel urbano ante el serio problema que el ruido supone para la salud física y psicológica de los ciudadanos. Con el objetivo de conocer el patrón de los niveles sonoros registrados en cada parque y la relación con las posibles fuentes sonoras, mediante la tecnología SIG e indicadores estadísticos de los datos muestrales procedentes del Plano Acústico de Madrid de 2002, se formula un método de análisis descriptivo de la intensidad y variabilidad del ruido y se aplica en cinco parques. Los hallazgos empíricos evidencian la elevada, y a veces desigual, intensidad sonora de los parques urbanos de Madrid, lo que permite valorar su idoneidad para las funciones de descanso, recuperación y disfrute.

Palabras clave: Ruido ambiental, parques urbanos, calidad ambiental, plano acústico, Madrid, SIG.

Noise and quietness in Madrid parks (Spain): a GIS based environmental case analysis

\section{ABSTRACT}

This research faces to analyze the environmental noise of Madrid urban parks, which should be rest and calm places in cities, due to the serious problem that noise means for citizens' physical and mental health. With the aim of determining the pattern of noise levels in parks and analysing its relations with the sound sources, it is developed a method to describe the intensity and variability of noise in five parks, using GIS technology and statistical techniques applied to 2002 Acoustic Map of Madrid data. The findings display the high and sometimes unequal sound intensity in the parks of Madrid, and allow gauging its suitability for resting, recovering and enjoying.

Key words: Environmental noise, urban parks, environmental quality, acoustic map, Madrid, GIS. 


\section{Nuisance et quiétude à l'intérieur des parcs de Madrid (Espagne): une ana- lyse environnementale de cas avec SIG}

\section{RÉSUMÉ}

Cet article étude le bruit environnementale dans les parcs urbaines de Madrid, lesquels devraient être lieux pour le repos et la tranquillité, considérant le sévère problème que le bruit produit sur la santé physique et psychologique des citoyens. A la fin de caractériser les niveaux sonores à chaque parc et analyser les possibles relations avec les sources sonores, une méthode pour décrire l'intensité et variabilité du bruit dans cinq parcs a été établi, utilisant systèmes d'information géographique et techniques statistiques et il a été appliqué aux données de la Carte Acoustique de Madrid 2002. Les résultats empiriques montrent la haute et parfois inégale intensité acoustique des parcs urbains à Madrid, permettant alors une appréciation de leur aptitude pour les fonctions de repos, récupération et plaisir.

Mots clés: Nuisance, parcs urbains, qualité environnementale, carte acoustique, Madrid, SIG.

\section{INTRODUCCIÓN}

La calidad de vida de los ciudadanos se está viendo afectada por una serie de problemas derivados de las condiciones ambientales cada vez más degradadas de las ciudades, entre los que la contaminación acústica destaca por las graves molestias que origina y por sus efectos sobre la salud física y psicológica, el descanso, el comportamiento y las actividades de las personas (Comunidad de Madrid, 1999). La multiexposición diaria al ruido (Sanz $\mathrm{Sa}$, 1987) ha ido configurando este problema como uno de los más embarazosos que hoy en día padece la sociedad urbana, fundamentalmente originado por el tráfico rodado, aunque también por las actividades de ocio nocturnas (Pérez Martos, 2003).

Este panorama hostil confiere especial valor a ciertos espacios dentro de la ciudad, como son los parques y zonas verdes, que deben aportar a los ciudadanos entornos cotidianos reparadores, de ocio y disfrute, revelándose como una de sus dotaciones principales, que debería paliar de algún modo la presión que los ambientes urbanos ejercen sobre la persona (Kaplan, 1983). Por ello, se trata de piezas fundamentales en la estructura y el planeamiento urbano (Brau et al., 1980) que contribuyen inequívocamente a la sostenibilidad. Aparte de un mero entorno verde, se configuran como escenarios de relación social, de ocio y deporte, de paseo y disfrute de la flora y fauna, de sosiego y descanso de las actividades diarias, aunque solamente sea por corto tiempo, aportando beneficios restauradores, sociales y sanitarios a los ciudadanos (vid. Rodríguez-Avial Llardent, 1982; Chiesura, 2004). En virtud de todas estas funciones, es deseable que estos entornos, aparte de limpios y seguros, sean tranquilos.

Además, la propia vegetación que albergan los parques puede actuar como una barrera física o pantalla para la dispersión de las ondas sonoras, mitigando sus efectos y molestias. Una pantalla vegetal tupida, según su especie y espesor, puede llegar a producir una cierta disminución del ruido percibido tras ella (Alonso Velasco, 1971). Por otra parte y, a pesar de la presión edificatoria, cada vez tienen mayor consideración los espacios verdes para mejorar la calidad del aire, oxigenar, refrescar (reducir el efecto de isla de calor) y hacer más respirable la atmósfera urbana, así como para 
contribuir a regularizar los flujos hídricos y el ruido, al tratarse de espacios abiertos y con vegetación.

A la luz de lo expuesto, y en una gran urbe como es Madrid, resulta de vital interés estudiar el ruido en sus parques y la intensidad con que éste se manifiesta, así como en qué medida estos espacios contribuyen a mitigar el problema de la contaminación acústica en la ciudad. En definitiva, interesa analizar la "salud acústica" de la que gozan sus parques, en virtud de las funciones beneficiosas que les son propias y que deberían hacerlos constituirse como espacios de sosiego dentro del dosel urbano. A tal fin, se contemplan aquí dos objetivos principales: por un lado, formular un método de análisis descriptivo de la intensidad y variabilidad del ruido en el interior de los parques urbanos de Madrid y, por otro, emitir un diagnóstico sobre la adecuación a las funciones de descanso, recuperación y disfrute, con miras a apoyar la gestión ambiental municipal en esta parcela competencial. En última instancia, se trata de evaluar este componente de la calidad ambiental exterior urbana en Madrid, cuestión que atañe a las metas contempladas en las políticas sobre ciudades saludables.

En definitiva, este estudio intenta aportar nuevas capacidades para el diagnóstico y, por ende, para afrontar ciertos problemas urbanos, facilitando la adopción de medidas de mantenimiento o correctoras, adecuadas para lograr unas ciudades más habitables y sostenibles, que contribuyan a la mejora del bienestar humano.

A continuación se exponen las exiguas referencias sobre el tema, para luego concretar el ámbito de estudio, los datos y la metodología adoptada. El siguiente apartado presenta los resultados alcanzados, seguido de una breve discusión y unas conclusiones.

\section{ESTADO DE LA CUESTIÓN Y OBJETIVOS}

El ruido viene caracterizado por unos rasgos, entre otros la intensidad, con una distribución singular en el tiempo y en el espacio, que resulta significativa para las actividades que en los espacios en cuestión se dan.

La presencia de sonido o inmisión sonora en el entorno es, además de un fenómeno físico, un fenómeno perceptivo, desde el momento en que los individuos presentes en ese entorno lo sienten, pudiendo convertirse en una molestia para su bienestar o un problema para su salud. Está aceptado que la degradación del ambiente urbano, y especialmente del sonoro, ha provocado que el ruido sea un problema serio para la salud física y psicológica de los ciudadanos, siendo prueba de ello que gran parte de las denuncias y quejas ${ }^{1}$ en materia ambiental planteadas ante las autoridades están relacionadas con esta causa. La acción de la administración madrileña se situó en una posición puntera aprobando ordenanzas al respecto desde hace tiempo, antes incluso

\footnotetext{
${ }^{1}$ Ello se refleja a menudo en informaciones de la prensa diaria. Véase como ejemplo esta noticia en el portal: http://www.madridiario.es/2010/Enero/madrid/sociedad/181447/mas60000-denuncias-ruido-madrid.html
} 
de la existencia de la Directiva 2002/49/CE sobre evaluación y gestión del ruido ambiental y de su transposición en la Ley 37/2003, del Ruido y sus posteriores desarrollos. Aparte de las ya citadas normas, hay que añadir que existen otras referencias que dan sentido a este trabajo entre las que destacan la Ordenanza de Protección contra la Contaminación Acústica y Térmica de 2011 del Ayto. de Madrid o el Plan General de Ordenación Urbana de Madrid de 1997.

Los parques y zonas verdes representan piezas clave dentro de la estructura urbana de la ciudad de Madrid, y este trabajo profundiza, de manera pionera, en el abordaje del problema de la contaminación acústica referido al ruido ambiental exterior en algunos de estos subconjuntos del espacio urbano, los más representativos.

La aportación aquí presentada se enmarca dentro de una línea de trabajo centrada en el análisis de la calidad acústico-ambiental del medio urbano (vid. Martínez Suárez y Moreno Jiménez, 2005 y 2006; Moreno Jiménez, 2007; Moreno Jiménez y Martínez Suárez, 2005; Martínez Suárez y Moreno Jiménez, 2009), en la que ya se diseñó una metodología para la determinación de los rasgos generales del ambiente acústico de los parques urbanos y zonas verdes. El estudio que ahora se presenta viene a profundizar y completar tales trabajos con carácter de detalle, intentando aportar una luz adicional al examen de la contaminación acústica en la ciudad de Madrid y, en concreto, a su afección sobre ciertos equipamientos urbanos que prestan distintos servicios a los ciudadanos.

No se conocen referencias de estudios previos enfocados al análisis detallado del ambiente acústico de las zonas verdes de Madrid, y ninguno de los trabajos consultados sobre espacios verdes urbanos se centra en detalle en el problema del ruido. En algunos se hace mención a la utilidad de las herramientas SIG en relación con el planeamiento urbanístico desde el punto de vista del inventariado de los usos del suelo, para el caso de los parques urbanos de la Comunidad de Madrid (Canosa Zamora et al., 2003), mientras que otros se centran más en los espacios públicos en general (Lladós Guerrero, 2006). Hay que destacar el esfuerzo que al respecto está haciendo el Ayuntamiento de Madrid por desarrollar un sistema de gestión eficiente e integrado de todo su patrimonio verde, a través de su Sistema de Información Geográfica de Gestión de Parques y Jardines (incluido en el SIG corporativo municipal, SIGMA), enfocado sobre todo a su inventariado y mantenimiento, aunque no a su gestión desde un punto de vista acústico.

Dejando a un lado el caso de estudio, en la bibliografía son escasas las referencias sobre el problema del ruido en los parques. Entre las recientes y más relevantes para nuestro interés pueden reseñarse solo unas pocas.

Lam et al. (2005) en un estudio sobre la calidad del aire y el ruido en setenta parques y espacios públicos de Hong Kong (China) en el que usaron como indicador sonoro el $\mathrm{L}_{\text {Aeq }}$ (entre las 7 y las $19 \mathrm{~h}$ ) hallaron que el nivel medio era superior a 65 dBA en todos los distritos, excepto en uno. Los parques más pequeños, alargados y próximos a grandes arterias de tráfico eran más ruidosos que los grandes; así mismo la variación intra-parque se manifestó importante, particularmente en los grandes parques, donde el ruido disminuía desde los bordes hacia el interior del parque de manera notoria. Tras comparar el ruido en los parques con el medido y estimado para 
zonas residenciales extraían la decepcionante conclusión de que no había evidencia de poder hallar más tranquilidad en los parques que en casa.

Zannin et al. (2006) evaluaron seis parques en la ciudad de Curitiba (Brasil) mediante el indicador $\mathrm{L}_{\text {Aeq, }}$, para lo que realizaron una toma de datos durante el período de 17-19 h por ser el de máxima afluencia de visitantes, situando los sonómetros durante 3 minutos en 303 puntos de los caminos más frecuentados. Los resultados mostraron que en cuatro parques no se superaban, como media, los $60 \mathrm{dBA}$ y en los otros dos, los más ruidosos, se alcanzaban los 64,8 y $67 \mathrm{dBA}$. Dado que usaron tres estándares de evaluación del ruido ( 50 y 55 dBA), algunos parques los cumplían pero no otros. En todo caso, se evidenció que los parques más céntricos, rodeados de vías de tráfico pesado y de zonas de alta actividad comercial no cumplían ninguno, por lo que planteaban que los parques no cumplían los fines previstos en la planificación, que había un problema de políticas y proponían diversas medidas.

Con un objetivo algo distinto, Brambilla y Maffei (2006) desarrollaron un experimento cotejando mediciones empíricas de intensidad sonora $\left(\mathrm{L}_{\mathrm{Aeq}}\right.$ y $\left.\mathrm{L}_{95}\right)$ en tres parques de la ciudad de Nápoles (Italia), con la valoración de diversos atributos de dichos parques, entre ellos la sonoridad, por parte de sendas muestras de individuos encuestados in situ, junto al lugar de medición. Los resultados evidenciaron que la sonoridad era considerada como muy importante por el $57 \%$ de los individuos, en promedio, aunque fue el aspecto menos importante de los seis evaluados (seguridad, paisaje, silencio, vegetación, aire puro y limpieza).

De lo expuesto se colige cuán escaso es el conocimiento sobre este aspecto del ambiente urbano y cómo los resultados preliminares apuntan a una calidad sonora baja, juicio que se sustenta solo sobre el atributo de intensidad del ruido. A tenor de lo anterior y asumiendo que los parques y jardines públicos, por el aporte al bienestar de los ciudadanos y a la mejora de la calidad de vida, son un tipo de dotaciones especialmente vulnerable al ruido, resulta oportuno plantearse: ¿cuál es el ambiente acústico de los parques más representativos de Madrid?, es decir, ¿qué niveles sonoros se soportan en su interior? A nivel de detalle, y desde un punto de vista espacial, interesa saber también cuál es la variabilidad sonora interna de los parques. A partir de ahí, y considerando la función reparadora y de sosiego que deben ejercer las zonas verdes ante el frenético ritmo de vida urbano, cabría indagar y valora si tales niveles sonoros son adecuados o dificultan dichas funciones. Para un apropiado abordaje de estas cuestiones se planteará aquí una propuesta metodológica sencilla, pero efectiva, si bien antes procede especificar los objetivos concretos avistados en el estudio:

1) Determinar y caracterizar sintéticamente el ambiente acústico interno de un significativo subconjunto de las dotaciones verdes urbanas del municipio de Madrid.

2) Formular un método de análisis descriptivo de la intensidad y variabilidad espacial del ruido en el seno de los parques urbanos, mediante un examen de detalle que haga aflorar su patrón espacial.

3) Enunciar un diagnóstico valorativo sobre la adecuación a las funciones de descanso, recuperación y disfrute que les son inherentes. 
En suma, se trata de establecer un procedimiento adecuado para diagnosticar en detalle el ambiente acústico de los parques urbanos, realizando una contribución basada en los datos sonoros del plano acústico de la capital y apoyada en las modernas tecnologías de la información geográfica mediante el empleo de los SIG, que posibilite la ulterior identificación y evaluación de la incidencia potencial que tiene el ruido ambiental de las zonas verdes sobre la población del municipio de Madrid próxima a ellas y que pueda servir de instrumento de ayuda para la planificación y gestión municipal. Con todo ello se intenta fomentar la explotación y clarificar la forma de emplear los planos acústicos como una herramienta de análisis y gestión para la mejora de la calidad de vida y la salud de las personas.

\section{3. ÁMBITO, MATERIALES Y MÉTODOS}

\subsection{EL CASO DE ESTUDIO}

Como objeto de análisis se ha seleccionado un subconjunto de los parques más representativos del municipio de Madrid. De entre las distintas categorías de zonas verdes contempladas a nivel municipal por el Plan General de Ordenación Urbana de Madrid (PGOUM) de 1997 ("uso dotacional zona verde"), las de interés para este estudio se enmarcan en estos dos grupos:

- Zonas Verdes Básicas (VB):

Parque de distrito: zonas ajardinadas o arboladas de superficie media y grande con diversidad de actividades que garanticen distintas posibilidades de esparcimiento dentro del ámbito distrital.

- Zonas Verdes Singulares (VS):

Parque urbano: incluidos dentro del tejido urbano, presentan, junto a los parques de distrito, una singularidad, bien en relación a su carácter histórico, bien por los equipamientos que en ellos se enclavan, lo que determina un ámbito de influencia a nivel de ciudad.

En el término municipal de Madrid existe una desigual distribución espacial de las zonas verdes: mientras que hacia el centro predominan las de reducido tamaño, ya sean de barrio o pequeños parques y jardines históricos, en las zonas del llamado Ensanche (originario del siglo XIX) y nuevos desarrollos urbanísticos periféricos son generalmente de mayor superficie y están dotadas de mayor cantidad de servicios. Asimismo, existe un elevado número de zonas verdes de borde en torno a grandes vías de comunicación. 
Existe una amplia normativa reguladora de la protección de las zonas verdes y de los elementos vegetales, de entre la que merecen destacarse la Ley 9/2001, del Suelo de la Comunidad de Madrid o la Ley 8/2005, de Protección y Fomento del Arbolado Urbano de la Comunidad de Madrid, entre otras. En lo que se refiere a la regulación concreta de las zonas verdes, el PGOUM remite a las Ordenanzas Municipales específicas aplicables.

\subsubsection{DELIMITACIÓN ESPACIAL Y TEMPORAL}

Aunque el ámbito de estudio potencial abarca la totalidad del término municipal de Madrid, estrictamente se ciñe al calificable como espacio urbano. Se trata de la ciudad más poblada de España, con unos efectivos que se mantienen alrededor de los 3 millones de habitantes desde los años setenta del pasado siglo (3,2 millones en enero de 2012 según el Ayto. de Madrid) y con una superficie aproximada de 60.709 ha.

La realización de este estudio cobra especial significado en una urbe como esta, considerada, según fuentes municipales, como una de las más arboladas del mundo, concretamente la segunda ciudad con más árboles de alineación en sus calles. Su Ayuntamiento promocionó y emprendió en 1998 el proyecto "Actuaciones de fomento y mejora del arbolado urbano y periurbano para el incremento de la calidad ambiental de la ciudad de Madrid", en el que se realizó un inventario exhaustivo de los aproximadamente 300.000 ejemplares existentes, y en 2003 se efectuó la primera revisión completa de todos los datos del inventario.

El ámbito estricto de interés han sido los parques urbanos. Habida cuenta de la variedad de espacios verdes existentes se hubo de proceder a una delimitación operativa de los mismos, partiendo de considerar un tamaño mínimo de ellos para que contuviesen en su interior un número de datos sonoros suficiente como para hacer emerger el patrón acústico intra-parque. Tras diversas consideraciones se estableció que esa superficie fuese igual o mayor a 20 ha (equivalente a 5 cuadrados del Plano Acústico) y además que el número de datos contenidos en el parque no fuese inferior a 15 . Ahora bien, de cara a la caracterización de los niveles sonoros asociados a cada parque, se contempló también el entorno próximo, a modo de banda sonora circundante, sobre la base de que éste también ejerce influencia sobre el ruido percibido dentro de sus límites. A tal fin se fijó una distancia de $141,5 \mathrm{~m}$ respecto al borde del parque, valor que se justifica más adelante.

Teniendo en cuenta los criterios establecidos podrían ser susceptibles de análisis quince parques (con una superficie igual o mayor a 20 ha y conteniendo 15 ó más centroides). Dado que la cifra de casos es demasiado alta para su presentación pormenorizada en los límites de este artículo, se han seleccionado cinco (vid. figura 1), por su relevancia y representatividad de los variados contextos de la ciudad: Parque del Buen Retiro (1), Parque del Oeste (2), Parque de la Cuña Verde de Latina (3), Parque de San Isidro (4) y Parque de Pradolongo (5). 
Figura 1. Localización de los cinco parques urbanos de Madrid seleccionados para el análisis.

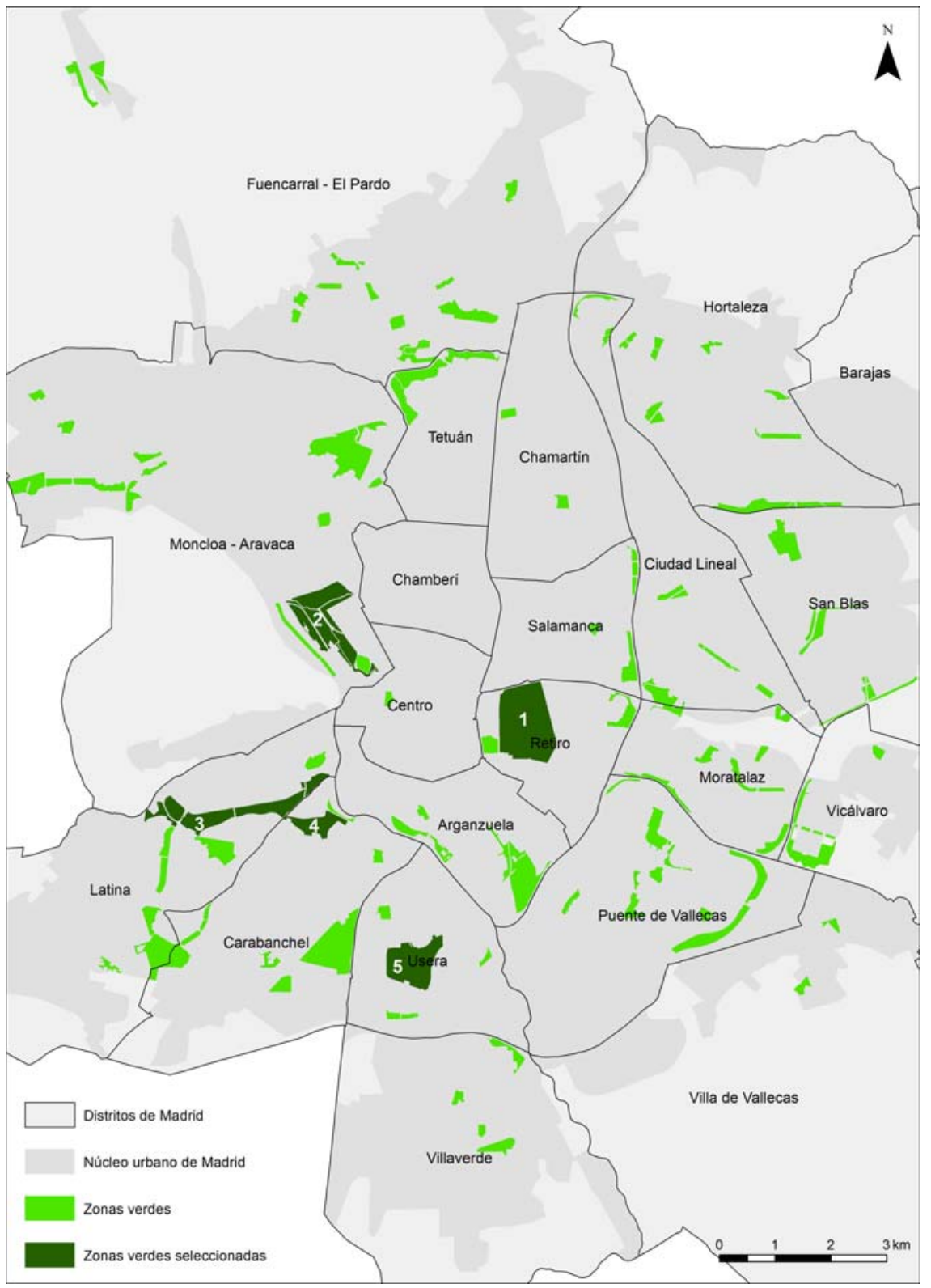

Fuente: Elaboración propia con datos del PGOUM. 
El momento temporal de referencia en este estudio corresponde al año 2002, fecha en la que fue publicado el Plano Acústico de Madrid del que provienen los datos de niveles sonoros empleados en el análisis. Aunque posteriormente se ha elaborado un nuevo Mapa Estratégico del Ruido (2007) para la ciudad, la inexistencia en él de datos sonoros sobre el interior de los parques lo hace inutilizable para los fines aquí perseguidos.

\subsection{LOS DATOS}

Las fuentes de datos ${ }^{2}$ conciernen a la información relativa a las zonas verdes por un lado y a la intensidad acústica exterior por otro. El modelo de geodatos para este análisis ya se preparó previamente en otros trabajos enmarcados en esta misma línea de investigación sobre caracterización general de las zonas verdes de Madrid (vid. singularmente Martínez Suárez y Moreno Jiménez, 2009).

En síntesis, la capa de zonas verdes de Madrid proviene de una selección de polígonos a partir de la cartografía digital oficial del último Plan General de Ordenación Urbana de Madrid de 1997, completada con otras fuentes. Por otro lado, la fuente para los datos sonoros corresponde al Plano Acústico de Madrid de 2002, para el cual se diseñó un muestreo espacial basado en una cuadrícula ortogonal regular que cubre la mayor parte del área urbanizada del municipio, en la que cada cuadrado mide 200 $\mathrm{m}$ de lado, a excepción del distrito de Centro, donde miden $100 \mathrm{~m}$ de lado.

Cada cuadrado de la cuadrícula tiene asociados unos niveles sonoros registrados en el interior del mismo, adoptando como indicador el $\mathrm{L}_{\text {Aeq }}$ (nivel sonoro continuo equivalente con una ponderación del tipo A), correspondiente a determinados periodos de medición (24 horas, diurno, nocturno), y expresado en decibelios (dBA). En este estudio, para la consideración del ambiente sonoro de cada zona verde se seleccionó el $\mathrm{L}_{\text {Aeq día }}(\mathrm{dBA})$ como indicador representativo del período entre las 7 y las 23 horas, de acuerdo con la función y usos propios de este tipo de dotaciones urbanas a las que se acude mayoritariamente durante dicho periodo diurno.

Como anteriormente se señaló, los datos considerados para caracterizar el ruido de cada parque comprenden los medidos en su interior y los situados en una franja circundante hasta 141,5 m. Como el lado de cada cuadrado del Plano Acústico mide $200 \mathrm{~m}$, la separación entre centroides será igualmente de $200 \mathrm{~m}$ (excepto en el ya mencionado caso del distrito de Centro, que será de $100 \mathrm{~m}$ ), de manera que la cifra propuesta responde a la distancia máxima de separación que podría existir entre el borde de un parque y el centroide más lejano de su entorno de influencia $(141,421 \mathrm{~m}$, equivalente a la mitad de la diagonal de los cuadrados), incrementada muy ligeramente para asegurar casos límite.

\footnotetext{
${ }^{2}$ Se desea agradecer al Ayto. de Madrid por la información cartográfica facilitada para la realización de este estudio.
} 


\subsection{TECNOLOGÍAS Y TÉCNICAS DE ANÁLISIS}

Para los parques seleccionados se ha tratado de examinar con detalle el patrón espacial y la variabilidad intra-parque del $\mathrm{L}_{\mathrm{Aeq} \text { dia }}$ en relación con su tamaño, forma, las actividades que soporta, las funciones urbanas del entorno y las principales fuentes generadoras de ruido. Fundamentalmente se ha empleado la tecnología SIG como instrumento para gestionar y analizar la información a través de un modelo de datos vectorial, con ArcGIS. La información cartográfica digital con la que se ha trabajado está proyectada y georreferenciada según el sistema vigente entonces en España (UTM-30, ED50).

Procedimentalmente, el SIG ha permitido efectuar la unión espacial de ambas capas de información, una poligonal (zonas verdes) y otra puntual (centroides de cuadrados del mapa acústico), con la consideración de un "buffer" de radio 141,5 m alrededor de cada polígono, a fin de calcular varios estadísticos sobre los valores de intensidad sonora diurna referidos a los centroides asociados a cada parque.

En suma, se han empleado técnicas convencionales de centralidad como la media y la mediana, así como medidas de dispersión como la desviación típica o la amplitud total. Complementariamente se ha obtenido la distribución de frecuencias de los valores de ruido.

Para visualizar y valorar el patrón del $\mathrm{L}_{\text {Aeq día }}$ en cada parque se ha realizado una doble cartografía: en primer lugar de situación, a partir de la imagen de satélite IKONOS de Madrid de 2006 proporcionada por la Dirección General de Desarrollo y Tecnologías de la Información del Ayto. de Madrid, y en segundo lugar acústica, con la delimitación espacial a partir de la capa de zonas verdes y mostrando la cuadrícula del Plano Acústico de Madrid, los centroides de cuadrados contenidos dentro de su entorno próximo y las calles próximas simbolizadas según los aforos de intensidad media diaria (IMD) del tráfico rodado de 2002, publicados por el Ayto. de Madrid.

\section{DESCRIPCIÓN Y ANÁLISIS DE RESULTADOS}

Antes del examen detallado de cada uno de los cinco parques, procede ofrecer una primera impresión comparativa de sus niveles sonoros y estadísticos.

La figura 2 muestra las distribuciones de frecuencias de intensidad sonora diurna $\left(\mathrm{L}_{\text {Aeq dia }}\right)$. En ella, a través de los histogramas, se puede apreciar cómo en todos los parques la mayoría de puntos muestrales presentan valores por encima del nivel sonoro máximo permitido de $65 \mathrm{dBA}$ establecido para las zonas verdes durante el periodo diurno en la Ordenanza de Protección de la Atmósfera contra la Contaminación por Formas de Energía del Ayto. de Madrid ${ }^{3}$, atenuándose esta tendencia en el

\footnotetext{
${ }^{3}$ Este límite sonoro máximo de 65 dBA establecido por la ordenanza del Ayto. de Madrid es coincidente con el recomendado por la Organización Mundial de la Salud (OMS).
} 
caso del Parque de San Isidro, que presenta un ambiente acústico algo más equilibrado en cuanto a cumplimiento. Los histogramas revelan por tanto una situación de moderada a importante superación del límite deseable, siendo el intervalo de 65-69 $\mathrm{dBA}$, en casi todos los casos, el que mayor número de puntos muestrales contiene.

Figura 2. Distribuciones de frecuencias de los puntos muestrales de la intensidad sonora diurna de cinco parques urbanos de Madrid.

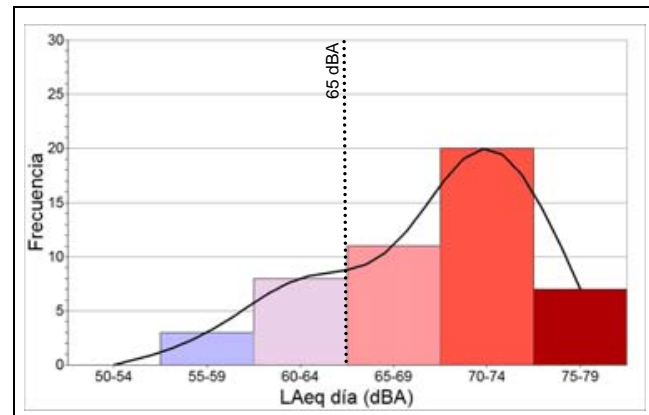

Parque del Buen Retiro

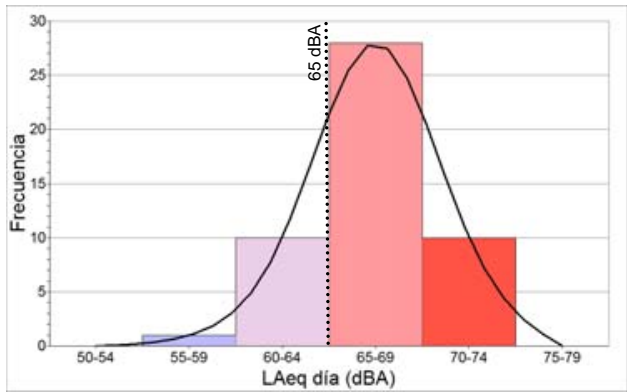

Parque de la Cuña Verde de Latina

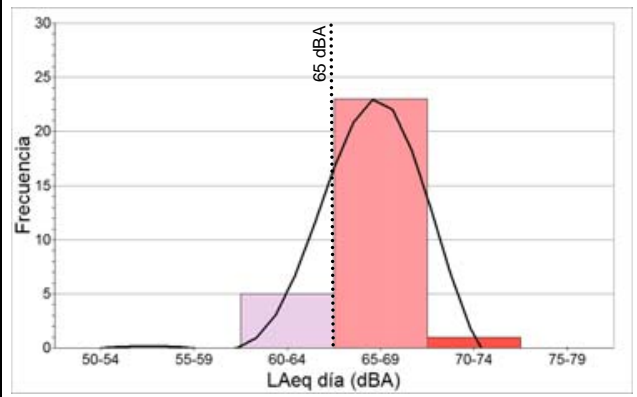

Parque de Pradolongo

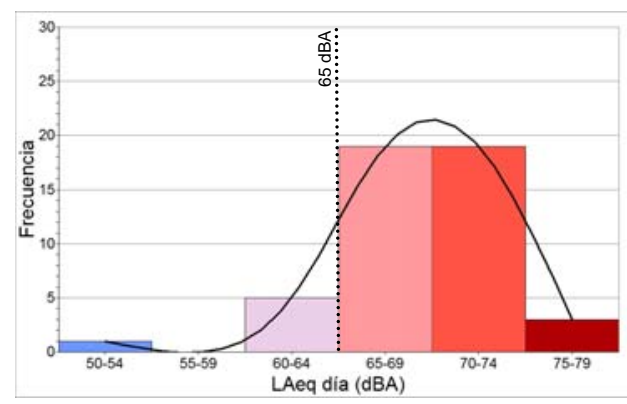

Parque del Oeste

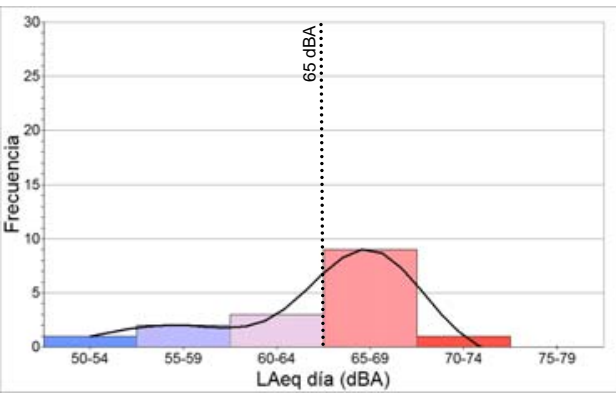

Parque de San Isidro

Fuente: Elaboración propia con datos del Plano Acústico de Madrid de 2002 
La tabla 1 completa este resumen de los hallazgos obtenidos, para cada uno de tales parques. En ella se constata que los estadísticos de centralidad superan, prácticamente en todos los casos, los niveles máximos permitidos de $65 \mathrm{dBA}$, si bien el Parque de San Isidro se sitúa en el límite. Los valores más altos de ruido exceden siempre este umbral crítico, mientras que los mínimos quedan casi todos por debajo, lo que indica contrastes acústicos notorios en el interior de tales parques. La importancia de esas diferencias internas se puede apreciar en las dos columnas de la derecha, predominando variaciones altas y medias y solo en un caso (Pradolongo) algo más débiles.

En resumen, el panorama inicial no resulta muy halagüeño, si bien parece que puede haber zonas intra-parque más sosegadas. Se examinará ahora cada uno de los parques en particular.

Tabla 1. Caracterización estadística del ambiente sonoro de cinco parques urbanos de Madrid.

\begin{tabular}{|c|c|c|c|c|c|c|c|c|c|}
\hline 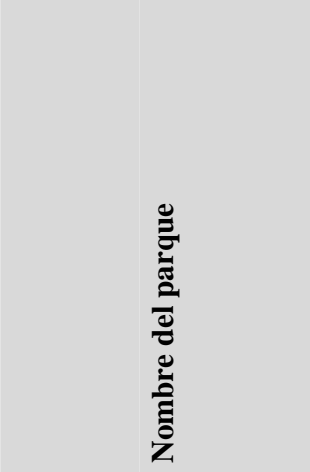 & 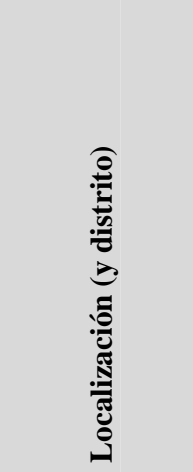 & 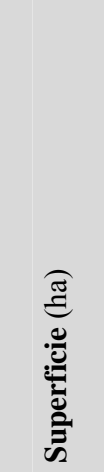 & 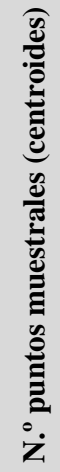 & 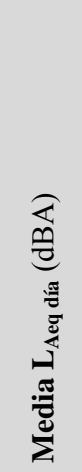 & 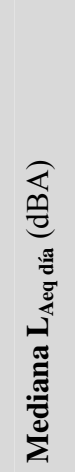 & 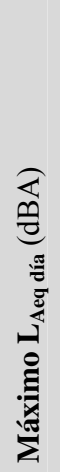 & 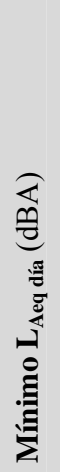 & 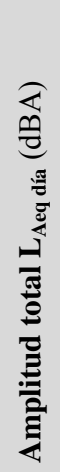 & 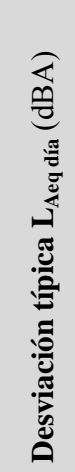 \\
\hline Parque del Buen Retiro & $\begin{array}{l}\text { Centro } \\
\text { (Retiro) }\end{array}$ & 118,18 & 49 & 68,9 & 70 & 77 & 56 & 21 & 5,01 \\
\hline Parque del Oeste & $\begin{array}{l}\text { Centro-O } \\
\text { (Moncloa- } \\
\text { Aravaca) }\end{array}$ & 75,60 & 47 & 68,8 & 69 & 77 & 54 & 23 & 4,26 \\
\hline $\begin{array}{l}\text { Parque de la Cuña } \\
\text { Verde de Latina }\end{array}$ & $\begin{array}{c}\text { SO } \\
\text { (Latina) }\end{array}$ & 72,91 & 49 & 66,9 & 67 & 73 & 58 & 15 & 3,12 \\
\hline Parque de San Isidro & $\begin{array}{c}\text { Centro-SO } \\
\text { (Carabanchel) }\end{array}$ & 23,93 & 16 & 63,9 & 65,5 & 70 & 54 & 16 & 4,87 \\
\hline Parque de Pradolongo & $\begin{array}{c}\mathrm{S} \\
\text { (Usera) }\end{array}$ & 60,53 & 29 & 66,8 & 67 & 71 & 62 & 9 & 2,09 \\
\hline
\end{tabular}

Nota: los valores máximos están representados en rojo y negrita, y los mínimos en azul y cursiva.

Fuente: Elaboración propia con datos del Plano Acústico de Madrid de 2002. 


\subsection{Parque del Buen Retiro}

Se trata de la zona verde histórico-artística más emblemática de la ciudad de Madrid, cuya superficie se ha mantenido protegida al margen de desarrollos urbanísticos que la afectaran, constituyendo hoy en día un singular enclave verde de gran entidad en pleno centro de la ciudad (figura 3), muy valorado tanto por los madrileños como por los foráneos y de visita obligada para los turistas. Se localiza en la zona centrooeste del distrito de Retiro y ocupa una extensión de 118 ha, presentando una forma aproximadamente rectangular y sin apenas desniveles. En su interior alberga diferentes edificaciones histórico-culturales (como el Palacio de Cristal, Palacio de Velázquez...), monumentos (estatua de Alfonso XII, del Ángel Caído...), fuentes, estanques, jardines, etc. y una gran cantidad de especies arbóreas y arbustivas de excepcional interés botánico. Es muy frecuentado a diario, ya sea para disfrutar de numerosas actividades culturales, recreativas, deportivas o simplemente de paseo o reunión, siendo posible perder de vista las fachadas de los edificios circundantes.

Figura 3. Parque del Buen Retiro y su entorno.

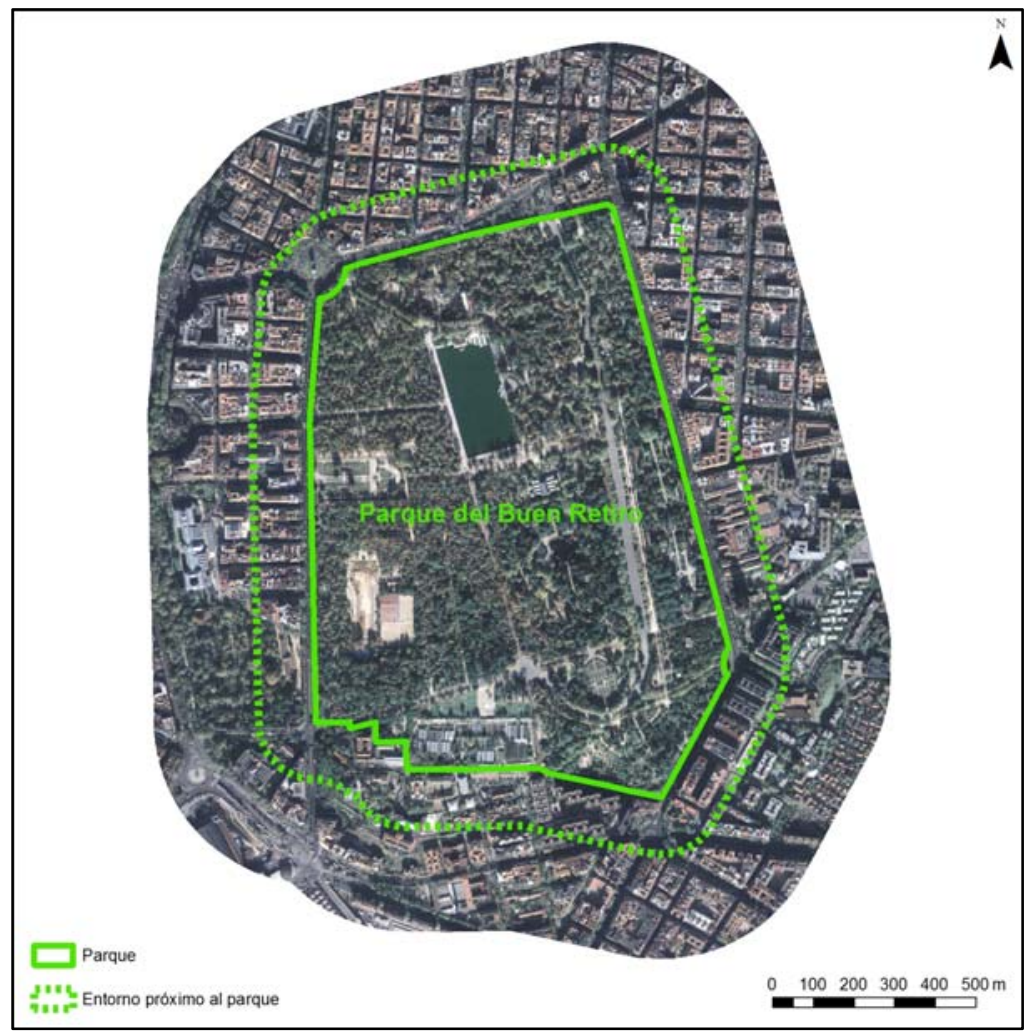

Fuente: Elaboración propia a partir de la imagen de satélite IKONOS 2006. 
Figura 4. AMBIENTE SONORO DEL PARQUE DEL BUEN RETIRO.

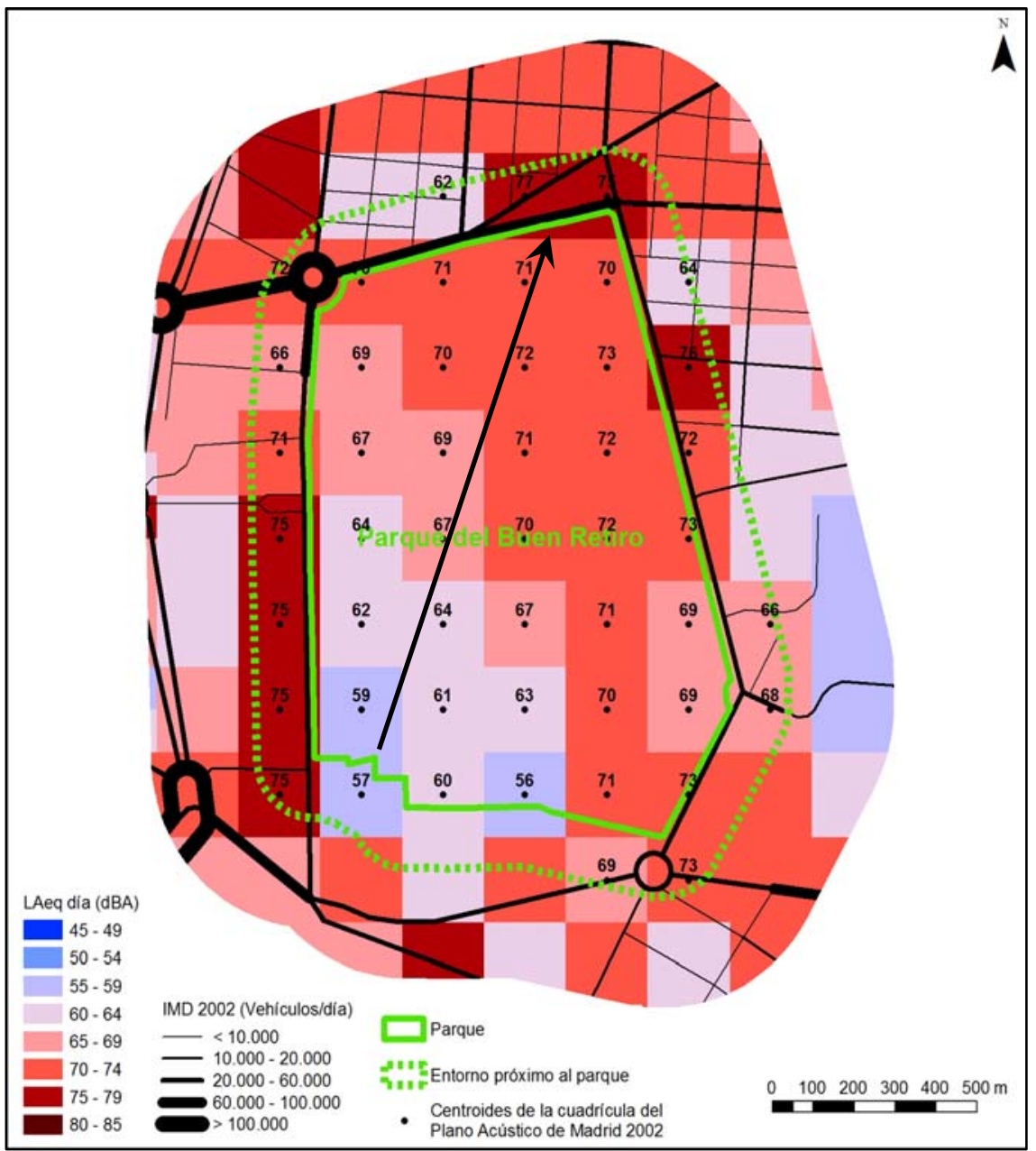

Nota: la flecha marca la tendencia espacial de aumento en los niveles sonoros.

Fuente: Elaboración propia con datos del PGOUM y del Plano Acústico de Madrid de 2002.

La extensión de su entorno sonoro da cabida a 49 centroides del Plano Acústico de Madrid, resultando un valor medio de $\mathrm{L}_{\text {Aeq día }}$ de $68,9 \mathrm{dBA}$ para el conjunto del parque, ciertamente elevado y que además supera el límite de $65 \mathrm{dBA}$ establecido en la ordenanza del Ayto. de Madrid. La mediana despunta igualmente, cuyo valor de $70 \mathrm{dBA}$ corrobora aún con más énfasis la afirmación anterior. Del conjunto de los 49 datos muestrales contenidos en su entorno, 38 (77,6 \%) exceden el límite aceptable normativamente de $65 \mathrm{dBA}$. La distribución de frecuencias de los puntos muestrales de la intensidad sonora diurna registrada en el parque (figura 2) indica, en línea con lo 
anteriormente comentado, que la mayoría de éstos superan el valor límite de $65 \mathrm{dBA}$, destacando especialmente el intervalo de 70-74 dBA, que corresponde a niveles sonoros bastante elevados. También, el intervalo de 75-79 dBA contiene un número de casos significativo, ello alerta de situaciones especialmente ruidosas. En contraste, se dan otras algo más sosegadas correspondientes a puntos muestrales de 60-64 dBA, próximos al límite recomendado pero sin llegar a superarlo. Sin embargo, es necesario examinar la variabilidad sonora interior para averiguar, en primer lugar, si este nivel se mantiene así de elevado por toda la superficie del parque y, a continuación, intentar explicar las posibles causas.

El nivel sonoro máximo registrado llega a ser muy alto, de $77 \mathrm{dBA}$, mientras que el mínimo, de $56 \mathrm{dBA}$, es suficientemente moderado para el periodo diurno considerado, lo que indica que su interior alberga rincones tranquilos. La amplitud sonora total es de $21 \mathrm{dBA}$, bastante grande, marcando destacables diferencias entre unas zonas y otras del interior del parque.

A la luz de estos datos parece que, a pesar del elevado nivel sonoro medio del parque, existe un patrón espacial con grandes contrastes acústicos registrados entre unas zonas y otras del interior. Este hecho se constata, además, por el elevado valor de la desviación típica, de 5,0 dBA, y cartográficamente es posible apreciarlo en la figura 4, en la que se puede observar una marcada gradación (según la flecha mostrada) de los niveles sonoros a la vista de las variaciones de color de los cuadrados del Plano Acústico, desde el sudoeste, donde se localizan las zonas más sosegadas (azules), hacia el nordeste y este, en donde se registran los valores sonoros más elevados (rojos).

En la figura 3 se puede observar el denso entorno urbano en el que se enclava el parque, mayoritariamente residencial de varias alturas. Hay que mencionar, al este, la presencia del Hospital Infantil Universitario Niño Jesús, y al oeste el Real Jardín Botánico, así como ciertas instalaciones administrativas próximas dispersas. Las fuentes de ruido que contaminan su interior son previsiblemente las grandes y transitadas vías que lo delimitan, con varios carriles de tráfico rodado en ambos sentidos. Para explorar esa hipótesis, en la figura 4 se han representado las vías aforadas en las que el Ayto. de Madrid ha obtenido datos de intensidad media diaria del tráfico, pudiendo observarse cómo los valores sonoros más elevados dentro del parque se corresponden con el entorno de las vías por las que circula un mayor número de vehículos al día. Al norte, la Plaza de la Independencia y la unión de las Calles de Alcalá y de O'Donnell y, al este, la Avenida de Menéndez Pelayo, determinan unos valores sonoros muy elevados en toda la zona norte y nordeste del parque. Al oeste, la Calle de Alfonso XII marca un eje ruidoso que lo delimita externamente. En contraposición, las zonas más tranquilas se localizan al sudoeste, en las proximidades del Observatorio Astronómico de Madrid, y al sur, en la zona de viveros, coincidiendo con un desnivel topográfico descendente hacia el sur, que estaría operando como barrera acústica. Fuera de los límites del parque los niveles sonoros aumentan hacia el sudoeste (en contacto con el Paseo de la Infanta Isabel), hacia el sudeste (Paseo de la Reina Cristina y Avenida del Mediterráneo), hacia el nordeste (Calles de O'Donnell y 
de Alcalá) y hacia el norte (Calles del Príncipe de Vergara, de Velázquez y de Serrano), todos ellos destacados ejes viarios.

En conclusión, el Parque del Buen Retiro se mantiene como una zona verde con especial identidad por su ubicación y singulares características, mezcla de caracteres botánicos, monumentales, culturales, históricos y deportivos, en la que, a pesar de la influencia de las grandes vías que la rodean y de la heterogeneidad de su ambiente sonoro, a la que también contribuyen las propias actividades que se realizan en su interior, es posible encontrar numerosos rincones tranquilos y acústicamente confortables donde descansar sin el ruido de la ciudad.

\subsection{PARQUE DEL OESTE}

Se localiza al oeste de Madrid, en el distrito de Moncloa - Aravaca, aunque muy próximo al centro urbano (apenas $1,5 \mathrm{~km}$ de la Puerta del Sol). Su disposición es alargada y en forma de " $\mathrm{L}$ " invertida, presentando fuertes desniveles entre las partes altas y bajas, pues ocupa una inclinada ladera descendente hacia el oeste, por donde discurre el Río Manzanares (figura 5).

Con una extensión de 75,60 ha, su entorno sonoro contiene 47 centroides del Plano Acústico de Madrid, cuyo valor medio de $\mathrm{L}_{\text {Aeq día }}$ es de 68,8 dBA, superando también el límite normativo municipal. Su mediana, de $69 \mathrm{dBA}$, es muy parecida a la media aritmética. Del conjunto de los 47 puntos muestrales $36(76,6 \%)$ superan el nivel aceptable de $65 \mathrm{dBA}$. En el histograma de la figura 2 la distribución de frecuencias de $\mathrm{L}_{\text {Aeq día }}$ revela una situación bastante desfavorable en la que los dos intervalos claramente mayores son los de 65-69 y 70-74 dBA. Van acompañados de algunos casos con niveles todavía aún más elevados (75-79 dBA) y, como contrapunto, un caso en el que la intensidad sonora es baja (50-54 dBA) y que claramente no logra compensar esta ruidosa situación.

Internamente, el comportamiento del nivel sonoro viene marcado por un máximo de $77 \mathrm{dBA}$, muy alto, y un mínimo bajo, de $54 \mathrm{dBA}$ (ambos valores prácticamente iguales a los del Parque del Buen Retiro), con una amplitud sonora total de $23 \mathrm{dBA}$, la cual es muy destacable.

Es necesario recurrir a la figura 6 para darse cuenta de que la distribución y la elevada variabilidad del $\mathrm{L}_{\text {Aeq dia, }}$ con una desviación típica de 4,3 dBA, viene determinada por la presencia de varias vías de comunicación internas al parque: Paseo de $\mathrm{Ru}$ perto Chapí, Paseo de Camoens y Valero, Calle de Francisco y Jacinto Alcántara, Calle de la Rosaleda y vías del tren de Cercanías, en dirección noroeste-sudeste (desde el Puente de los Franceses hasta la Pza. de España), cuya circulación de vehículos se convierte en una fuente sonora que rompe la posible tranquilidad. Hacia el este, los niveles sonoros también aumentan según nos acercamos a las vías que canalizan el tráfico del cuadriculado barrio de Argüelles colindante con el parque (Paseo del Pintor Rosales, Calle de Ferraz y Calle de Irún), mientras que hacia el oeste tienden a disminuir (Río Manzanares). 
En resumen, se trata de un parque bastante singular por su forma y ubicación, cuyos niveles y variabilidad acústicos resultan bastante parecidos en conjunto a los del Parque del Buen Retiro, aunque con la peculiaridad de que las vías interiores dificultan especialmente la posibilidad de encontrar lugares sosegados en su seno.

Figura 5. Parque del Oeste y su entorno.

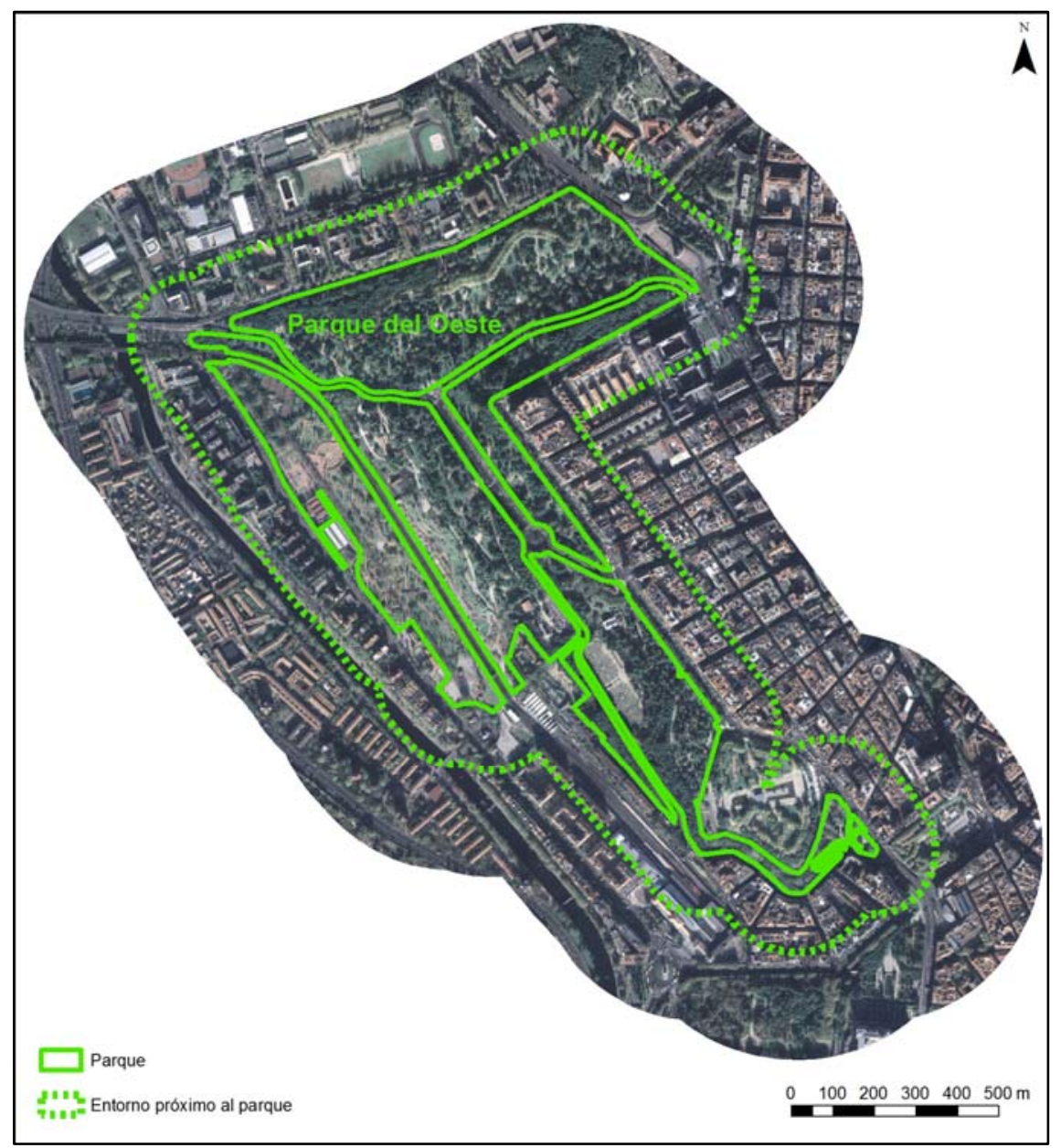

Fuente: Elaboración propia a partir de la imagen de satélite IKONOS 2006. 
Figura 6. Ambiente sonoro del Parque del Oeste.

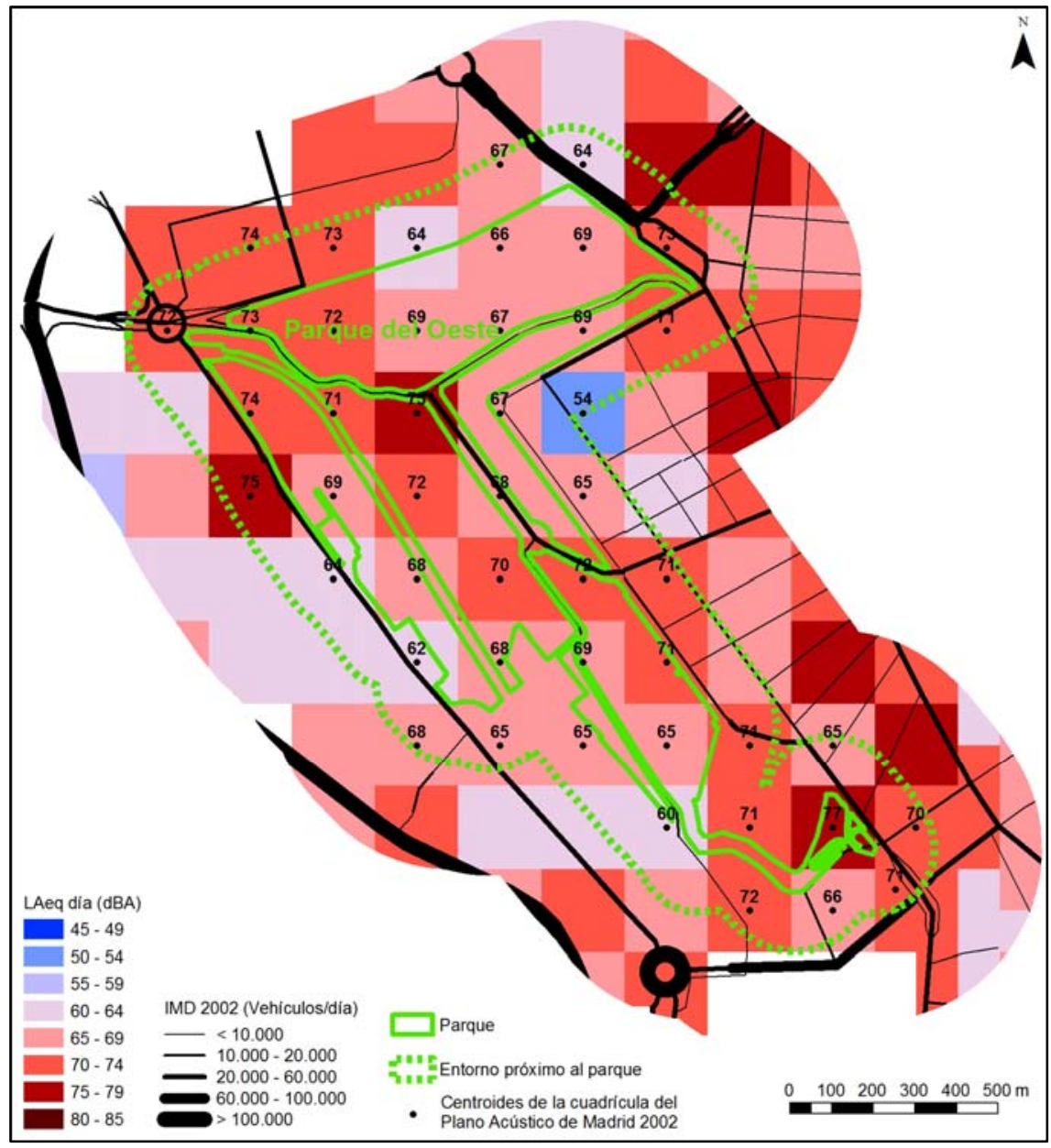

Fuente: Elaboración propia con datos del PGOUM y del Plano Acústico de Madrid de 2002.

\subsection{PARQUE DE LA CUÑA VERDE DE LATINA}

Se ubica al sudoeste de la ciudad, en el distrito de Latina, y muestra una forma muy alargada en sentido este-oeste (figura 7). Presenta una extensión de 72,91 ha y su entorno sonoro contiene 49 centroides del Plano Acústico de Madrid, tantos como el Parque del Buen Retiro, a pesar de que ocupa casi la mitad de superficie. Su valor medio de $\mathrm{L}_{\text {Aeq día }}$ es de 66,9 dBA, superando también el límite normativo municipal, y su mediana es de $67 \mathrm{dBA}$. Del conjunto de los 49 puntos muestrales contenidos en su entorno, $34(69,4 \%)$ exceden el nivel aceptable de $65 \mathrm{dBA}$. 
Figura 7. Parques de la Cuña Verde de Latina y de San Isidro y su entorno.

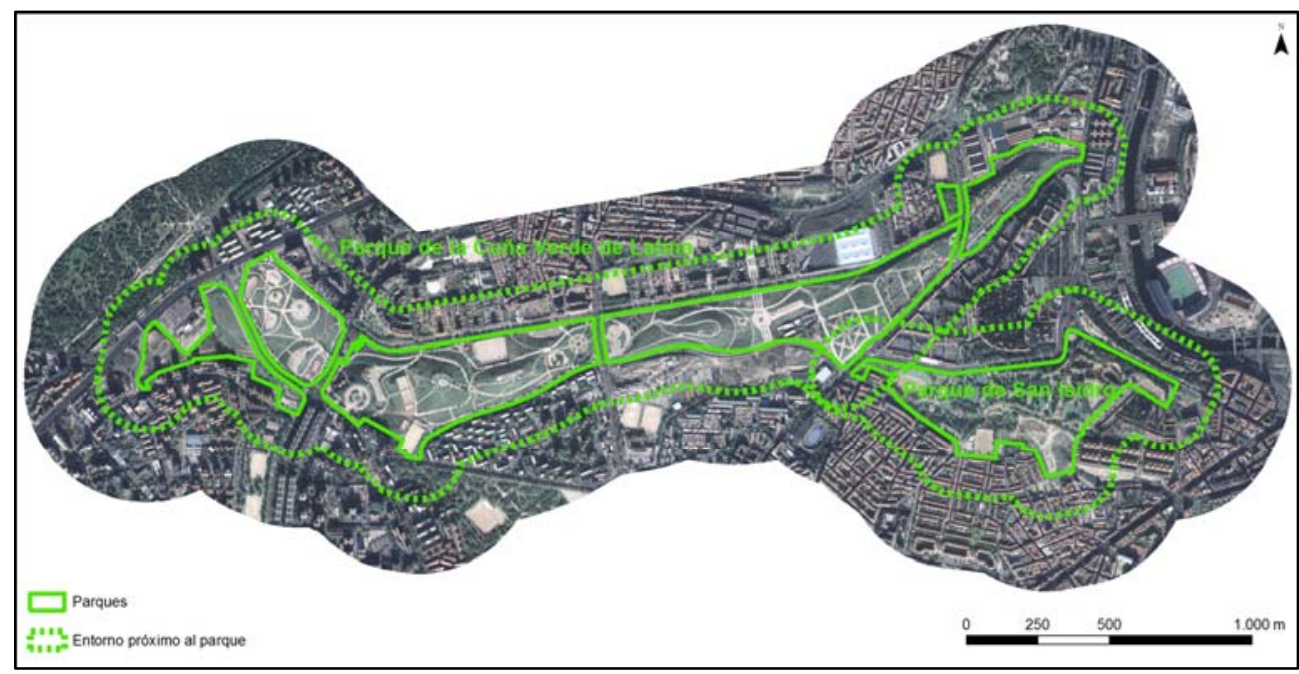

Fuente: Elaboración propia a partir de la imagen de satélite IKONOS 2006.

En su interior, el nivel sonoro máximo registrado es de $73 \mathrm{dBA}$, bastante alto, y el mínimo moderado, $58 \mathrm{dBA}$, lo que se traduce en una variabilidad media (amplitud total de $15 \mathrm{dBA}$ y desviación típica de 3,1 dBA). La distribución de los datos sonoros del parque (figura 2) muestra cómo casi todos sus puntos muestrales se reparten en sólo tres intervalos agrupados en torno al límite normativo. Una clara mayoría posee valores sonoros entre 65 y $69 \mathrm{dBA}$, es decir, superándolo. A partir de ahí, existe un grupo aún más ruidoso (70-74 dBA), pero también otro con niveles aceptables (60-64 $\mathrm{dBA}$ ), que de algún modo puede significar un cierto efecto compensatorio.

En la figura 8 se puede observar cómo los niveles sonoros predominantes son algo elevados, con un patrón espacial bastante uniforme a lo largo de la alargada superficie del parque, y aumentos en los extremos. Aunque se trata de una zona en la que no se dispone de datos de IMD del tráfico, el ruido es probablemente debido a su trazado paralelo a la Calle del Concejal Francisco José Jiménez por el norte, Calle de Cuart de Poblet por el sur y la Vía Carpetana por el este, una situación pues circundada por vías. Los niveles sonoros tienden a incrementarse en la zona oeste debido a la proximidad del enlace entre la Calle de los Yébenes y la de Valmojado, así como por la cercanía al Paseo de Extremadura (A-5). Los cuadrados representados en azul, ya fuera del parque, a la altura de su tramo medio al norte y al sur, corresponden a zonas mayoritariamente residenciales. 
Figura 8. Ambiente sonoro de los Parques de la Cuña Verde de Latina y de San Isidro.

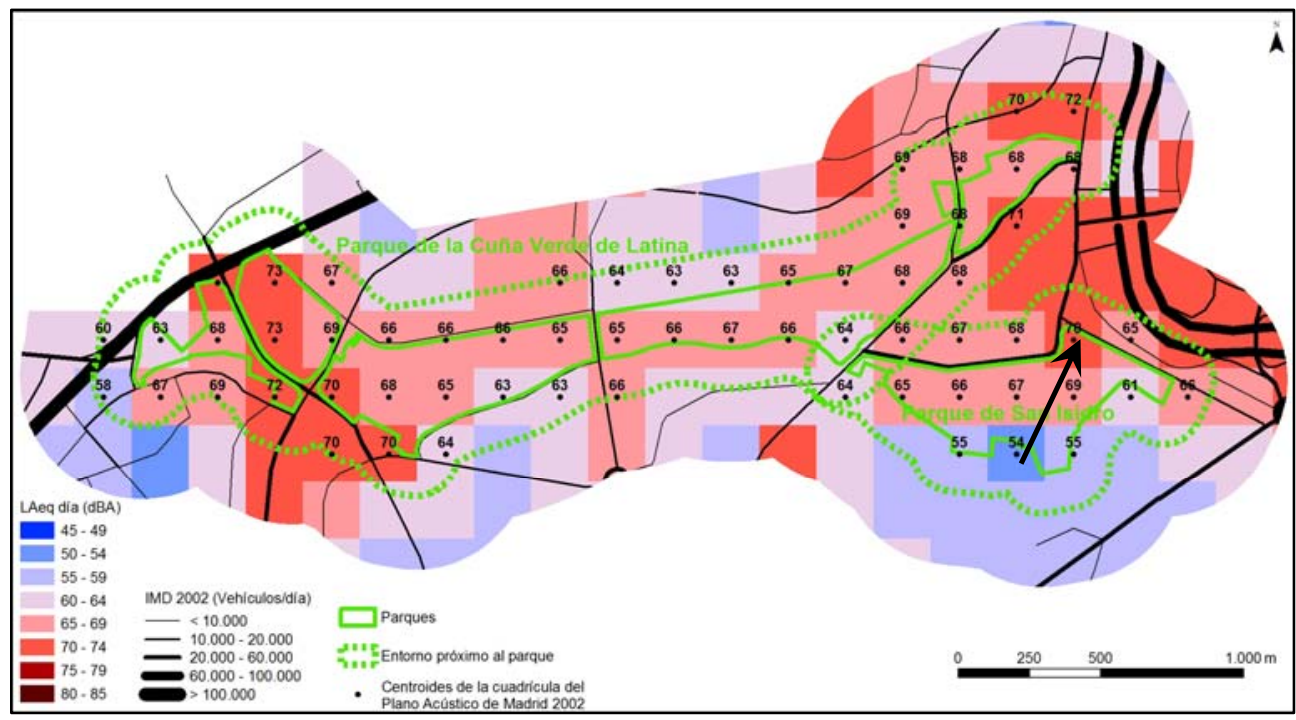

Nota: la flecha marca la tendencia espacial de aumento en los niveles sonoros.

Fuente: Elaboración propia con datos del PGOUM y del Plano Acústico de Madrid de 2002.

En resumen, se trata de un parque que, por su forma alargada y paralelismo con las vías que lo circundan, no consigue albergar áreas suficientemente tranquilas, presentando unos niveles sonoros relativamente homogéneos y la vez algo altos.

\subsection{PARQUE DE SAN ISIDRO}

Se localiza en la zona sudoeste de la ciudad, en el distrito de Carabanchel. Aunque está fuera de la llamada "almendra central" de Madrid, se encuentra relativamente próximo al centro urbano. Presenta una forma un tanto alargada, en dirección esteoeste, y una topografía con superficie aplanada en la parte alta y bajadas en talud hacia las vías circundantes, por lo que queda elevado respecto al entorno en la mayoría de su perímetro (figura 7).

Su extensión es de 23,93 ha, bastante menor que la de los restantes casos analizados, y su entorno sonoro da cabida a 16 centroides del Plano Acústico de Madrid, con un valor medio de $\mathrm{L}_{\text {Aeq día }}$ de $63,9 \mathrm{dBA}$, cumpliendo por tanto el límite de $65 \mathrm{dBA}$ establecido en la ordenanza del Ayto. de Madrid, aunque su mediana lo excede levemente $(65,5 \mathrm{dBA})$, por lo que la mitad de los datos muestrales contenidos en su entorno superan aquél límite. Por su pequeña extensión no contiene tantos puntos muestrales en su interior como otros parques aquí estudiados, aunque sí posee un número suficiente. En el histograma de la figura 2 se puede ver cómo, al igual que en el resto de parques analizados, el intervalo con mayor número de puntos muestrales es 
el de 65-69 dBA, aunque aquí hay más casos con valores sonoros bajos que sí cumplen el límite recomendado y que le confieren, por tanto, un ambiente más sosegado.

En su interior, el nivel sonoro máximo registrado llega a ser algo alto, $70 \mathrm{dBA}, \mathrm{y}$ el mínimo es $54 \mathrm{dBA}$, el más bajo de los parques estudiados. La amplitud sonora total es de $16 \mathrm{dBA}$, media en comparación con el resto de casos, y muy similar a la de la Cuña Verde de Latina, aunque ocupa prácticamente 1/3 de la superficie de esta última. Ello, junto a su importante desviación típica, de 4,9 dBA, anticipa una notable variabilidad interior.

La figura 8 muestra las diferencias en los niveles registrados, pudiéndose apreciar una tendencia espacial clara con una progresión (obsérvese la flecha en la figura) desde las zonas más tranquilas del sur, hacia el norte, donde se alcanzan los valores sonoros más elevados, hacia el Paseo de la Ermita del Santo y su enlace con el Paseo del Quince de Mayo (en dirección hacia el Estadio Vicente Calderón, en la otra orilla del Río Manzanares).

En general, el entorno urbano en el que se sitúa el parque es bastante tranquilo. La figura 7 permite observar el parque y sus alrededores, con las posibles fuentes de ruido que contaminan su interior desde el norte, fundamentalmente las recién mencionadas vías rodadas. Hay que añadir que, al encontrarse elevado sobre dichas vías, los taludes perimetrales ejercen una función de barrera acústica que mitiga algo la percepción del ruido en ciertas partes de su interior. Así, el contacto en forma de talud con la zona residencial del barrio de San Isidro confiere a la parte del sur del parque un ambiente más calmoso.

En definitiva, se trata de un parque medianamente ruidoso, en el que coexisten zonas con niveles sonoros que superan lo aceptable, aunque no demasiado, con otras de niveles tolerables, dibujándose unas diferencias acústicas y una gradación bien definidas, que no obstante permiten encontrar rincones suficientemente sosegados.

\subsection{PARQUE DE PRADOLONGO}

Se localiza al sur, algo alejado de la almendra central, en el corazón del distrito de Usera. Presenta una superficie más o menos rectangular y plana (figura 9). Su extensión es de 60,53 ha, y su entorno sonoro contiene a 29 centroides del Plano Acústico de Madrid, con un valor medio de $\mathrm{L}_{\mathrm{Aeq} \text { dia }}$ de $66,8 \mathrm{dBA}$, superando el límite normativo municipal y muy parecido al valor registrado en la Cuña Verde de Latina. Su mediana es de $67 \mathrm{dBA}$, igual que en el caso del recién citado parque. Del conjunto de los 29 datos muestrales contenidos en su entorno, 22 (75,9\%) exceden el nivel aceptable de $65 \mathrm{dBA}$. El panorama acústico mostrado a través de su histograma (figura 2) revela que los valores del $\mathrm{L}_{\text {Aeq dia }}$ se distribuyen en tres grupos, de forma parecida a la anteriormente comentada del Parque de la Cuña Verde de Latina, en cuanto a la clara predominancia de niveles de 65-69 dBA, con la diferencia de que el intervalo más ruidoso es muy reducido y le gana en importancia el de 60-64 dBA, de valores aceptables. Por tanto parece poseer un ambiente acústico bastante homogéneo aunque desfavorable. 
Figura 9. Parque de Pradolongo y su entorno.

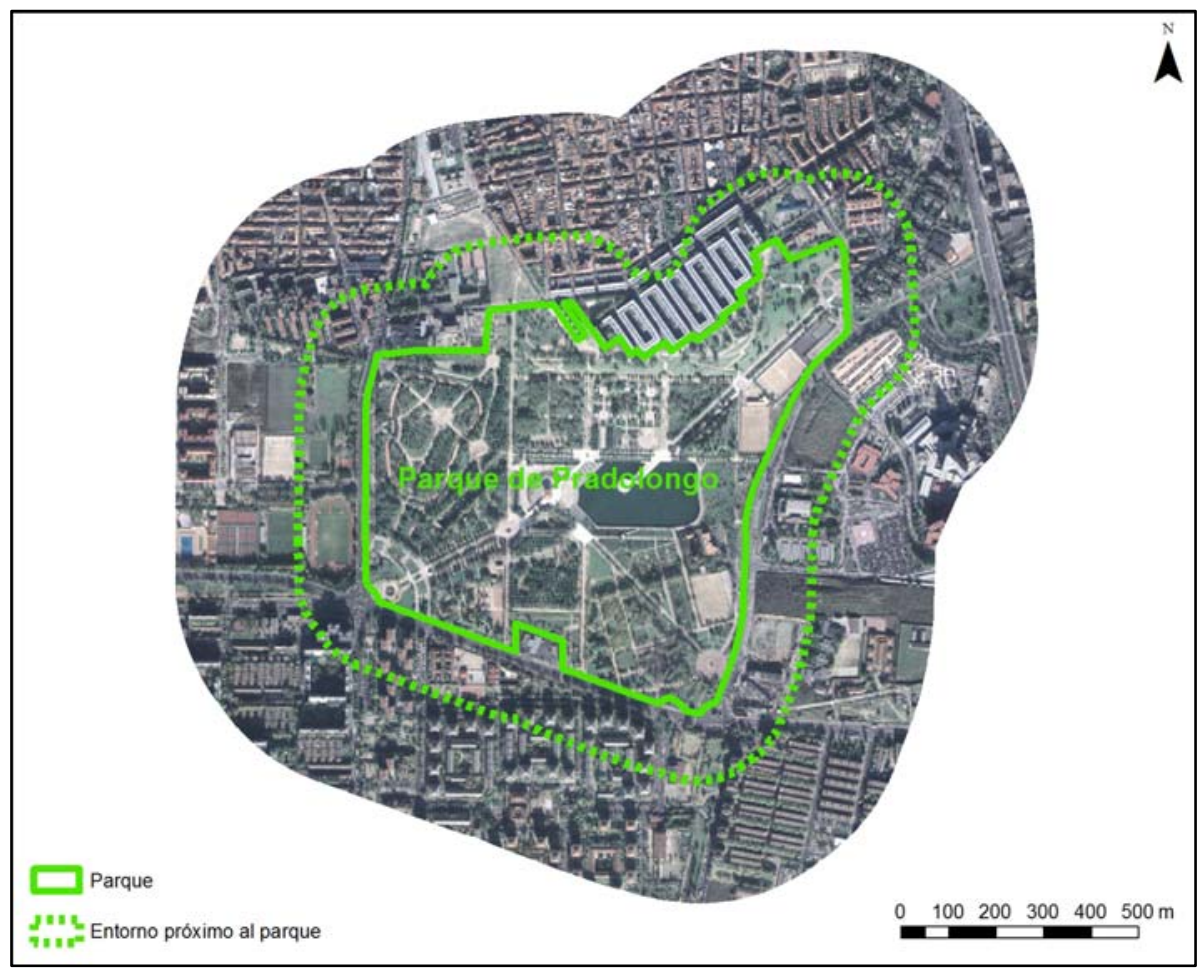

Fuente: Elaboración propia a partir de la imagen de satélite IKONOS 2006.

El nivel sonoro máximo registrado llega a ser alto, $71 \mathrm{dBA}$, y el mínimo es moderado, $62 \mathrm{dBA}$, con una amplitud sonora total bastante pequeña, de $9 \mathrm{dBA}$. La tendencia que se vislumbra, a la vista de estos datos, es la de un nivel sonoro medio-alto repartido uniformemente por toda la extensión del parque, circunstancia que viene apoyada por el valor relativamente bajo de la desviación típica, de 2,1 dBA (la menor de los casos detallados estudiados).

La ausencia de variaciones de color dentro de la superficie del parque, que se puede observar en la figura 10, revela las escasas diferencias en los niveles sonoros registrados en el mismo. Fuera de sus límites, hacia el norte (tras la Calle del Cristo de la Victoria) y sur (tras la Avenida de los Poblados) el ruido ambiental tiende a disminuir al tratarse de zonas residenciales, concretamente los barrios de Orcasitas y Orcasur. En cambio, se mantiene hacia las instalaciones deportivas situadas al oeste (tras la Avenida de Rafaela Ibarra) y también hacia el este (tras la Calle del Doctor Tolosa Latour), posiblemente por la realización de las obras de ampliación del complejo hospitalario universitario 12 de Octubre. 
Figura 10. Ambiente sonoro del Parque de Pradolongo.

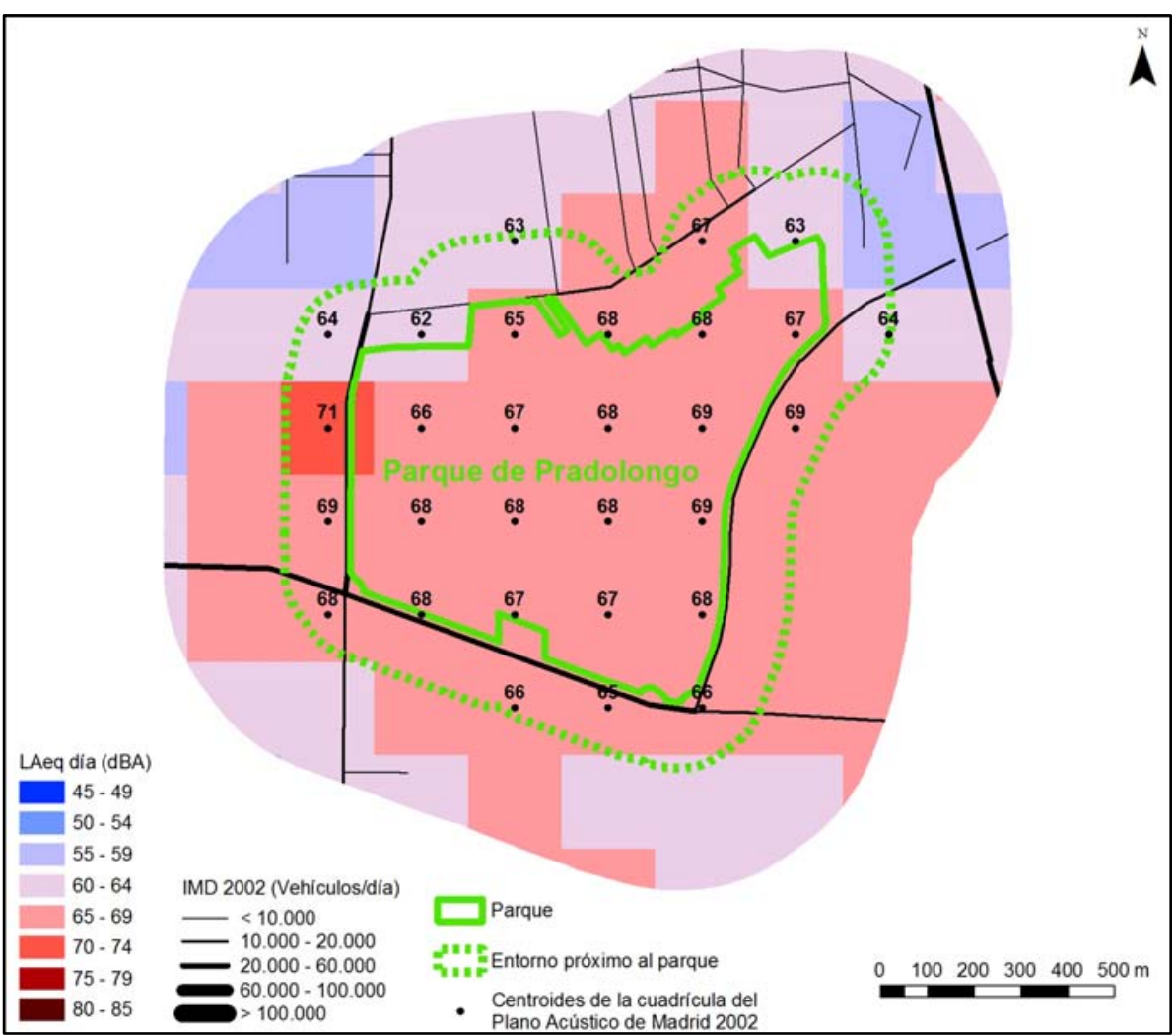

Fuente: Elaboración propia con datos del PGOUM y del Plano Acústico de Madrid de 2002.

Presenta una situación circundada por vías, aún más marcada a como sucedía en el caso de la Cuña Verde de Latina. Los datos de IMD del tráfico muestran un moderado flujo rodado por tales vías (al norte, sur, este y oeste), circunstancia que parece motivar los elevados y homogéneos niveles sonoros que se registran en el interior del mismo, a la vez que por otra parte destacan las tranquilas calles situadas más al norte.

En resumen, se trata de un parque con niveles sonoros medio-altos y muy homogéneos a lo largo y ancho de su superficie.

\section{DISCUSIÓN}

El trabajo aquí presentado avanza en el conocimiento del problema de la contaminación acústica en las ciudades y, en particular, en el caso de Madrid. Concretamente se ha establecido el grado de afección por ruido ambiental en unos equipamientos urbanos, como son las zonas verdes, que deberían prestar ciertas utilidades a los ciudadanos, en particular sosiego y gratificación sonora. 
La cobertura regular de los datos (basada en un muestreo espacial equidistante) difiere y es más representativa que la de otros estudios, en los que se han priorizado ciertas zonas, por ejemplo las más frecuentadas por los ciudadanos, como hicieron Zannin et al. (2006). Lam et al. (2005), sin embargo, a partir de un muestreo espacial irregular, estimaron luego con un modelo los niveles de ruido internos en cada uno de los parques, lo que les permitió subsanar esa limitada representatividad.

En todo caso, la fuente disponible de datos sonoros ha permitido adoptar un método con finalidad descriptiva relativamente sencillo, pero efectivo para la evaluación ambiental, apoyado en un tratamiento con SIG y técnicas estadísticas. Estas técnicas han podido ser algo más completas y variadas que en los análisis de otros autores, por cuanto no se trataba de estimaciones, sino de datos observados y con cobertura total.

Ello ha posibilitado, primero, conocer el patrón general de los niveles de ruido registrados en cada parque (cuestión que también lograron Lam et al. 2005), analizar su variabilidad interior en relación con su morfología y poner aquéllos en relación con las posibles fuentes sonoras de su derredor. No obstante, el tamaño algo excesivo de la cuadrícula muestral impide llegar a mayor detalle en ciertas zonas significativas. Los patrones de ruido intra-parque hallados muestran algunas claras similitudes con los de otros lugares, en particular la disminución del ruido hacia el interior del parque y el notable impacto que tienen las vías de alto tráfico circundantes sobre los niveles sonoros de la franja más exterior de los parques.

Por lo que respecta a la idoneidad de dichos niveles sonoros para la función de descanso que estos espacios verdes deben brindar, cabe advertir en primer lugar que en los diferentes trabajos se aplican estándares de aceptación diferentes, lo que hace que las valoraciones no sean totalmente comparables. Ello no obsta para que los autores consultados, al igual que sucede en este estudio, se pronuncien negativamente sobre el ruido excesivo existente en los parques urbanos, aunque puedan hallarse ámbitos dentro de ellos que cumplen los límites recomendados por las normativas y por tanto resulten más saludables.

\section{CONCLUSIONES}

Las zonas verdes constituyen equipamientos imprescindibles y necesarios para el equilibrio de la urbe y la calidad de vida de los ciudadanos, siendo parte y función del medio urbano y desempeñando un importante papel en la regulación y reducción de un problema ambiental y social tan crítico como es el del ruido, y por otra parte aportan un valor especial y personalidad propia a muchas ciudades, como la capital madrileña.

La atención a su dimensión acústica ambiental resulta extraordinariamente exigua por parte de la comunidad científica, pero también por las instancias políticas y por la ciudadanía. En este artículo se ha pretendido realizar una aportación en ese sentido, profundizando en la indagación que anteriormente los autores llevaron a cabo para el conjunto de los parques de la ciudad de Madrid. El foco se ha centrado en determinar el ambiente acústico interno de una muestra de dotaciones verdes urbanas, seleccionadas por su representatividad y significación dentro del municipio de Madrid. Para 
ello, se ha formulado un método de análisis descriptivo de la intensidad y variabilidad espacial del ruido en el interior de los parques urbanos, con un tratamiento de detalle que ha permitido identificar su patrón espacial. Y finalmente se ha podido enunciar un diagnóstico valorativo sobre la adecuación a las funciones de descanso, recuperación y disfrute que les son propias.

Al respecto, debe subrayarse que resulta factible abordar más eficientemente las problemáticas ambientales urbanas en relación con la evaluación de la intensidad acústica a través de las tecnologías de la información geográfica. Con ellas y la concurrencia de técnicas gráficas y estadísticas se ha posibilitado el entendimiento de ciertas relaciones de forma más clara. La metodología aquí planteada ha ilustrado una forma de explotar los planos acústicos como una herramienta de análisis y gestión ambiental que se considera aplicable a otras ciudades en las que se disponga de un modelo de datos similar.

En lo concerniente a las fuentes es de destacar la valiosa información recogida en el Plano Acústico de Madrid de 2002, si bien es preciso añadir que el propio diseño del Plano ha introducido ciertas limitaciones a la capacidad del análisis. Por un lado, la estructuración cuadriculada de la información sonora ha supuesto un importante encorsetamiento que ha habido que solventar mediante la conversión puntual a sus centroides; por otro, el desconocimiento de la localización exacta de los puntos muestrales a partir de los cuales se elaboró. No hay que olvidar, además, que los datos sonoros divulgados en el Plano son enteros, resultantes de un redondeo, lo que supone un cierto grado de inexactitud, que tampoco fue enmendable en este trabajo. El paso de malla de $200 \mathrm{~m}$ de la cuadrícula también parece algo desajustado (por excesivo) a los efectos de estudios de detalle como el abordado aquí. En las zonas en donde dicha equidistancia ronda los $100 \mathrm{~m}$ (como en el distrito de Centro) se dispone de un grado de información mucho más rica, matizada y entendemos que suficiente y acorde con la "rugosidad" geométrica de los entornos urbanos que se trata de caracterizar.

Dado que el ruido viene determinado por una distribución concreta en el tiempo y en el espacio, significativa para las actividades que en los espacios en cuestión se dan cobra sentido considerar especialmente el periodo temporal diurno para el estudio acústico de las zonas verdes, por sus horarios de uso dominante. Pero, y también en relación con la información sonora, sería deseable obtener un muestreo acústico temporal detallado que pudiera poner de manifiesto la relación entre niveles sonoros en el parque, preferencias y conductas de frecuentación de sus usuarios, por ejemplo sabiendo que éstos son visitados mayoritariamente en horas de luz diurna, sobre todo por las tardes tras la salida de la población infantil de los colegios o en fines de semana. Estudios como el de Brambilla y Maffei (2006) resultan encomiables en ese sentido y abren sugestivas posibilidades a la indagación.

Desde el punto de vista de los hallazgos procede recordar que la presencia de sonido en el entorno es, además de un fenómeno físico, un fenómeno perceptivo, desde el momento en que los individuos presentes en ese entorno lo sienten, pudiendo convertirse en un problema para su salud o una molestia para su bienestar, especialmente en entornos donde precisamente se busca sosiego. El examen del cumplimiento 
de los límites legales contemplados por la normativa municipal para los parques estudiados muestra unos resultados insatisfactorios, pues todos menos uno rebasan los niveles recomendables (según los estadísticos de centralidad), aunque en ciertos casos no mucho.

Aunque la propia vegetación, como elemento destacado en los parques y zonas verdes, pueda llegar a producir una cierta disminución del ruido percibido tras ella al actuar como una barrera física o pantalla para la dispersión de las ondas sonoras, otras claves importantes para la reducción de los efectos y molestias generados por el ruido urbano radican en el propio planeamiento urbanístico, los avances tecnológicos y la mejora de la conducta cívica del ciudadano.

El estudio de detalle del ambiente sonoro interno de algunos parques representativos de la ciudad revela diferentes patrones de variabilidad intra-parque del $\mathrm{L}_{\text {Aeq día, }}$ en función de su tamaño, la topografía, las actividades que soportan y las funciones urbanas del entorno en el que se ubican, particularmente las vías de tráfico cercanas o interiores. Ello abre el camino para adoptar medidas correctoras que garanticen unos parques con superior placidez y calidad ambiental.

En resumen, este trabajo ha intentado proporcionar un esquema metodológico sencillo a las administraciones públicas para la caracterización y valoración de los espacios verdes públicos desde el punto de vista de su tranquilidad ambiental y, por ende, de su idoneidad para que los ciudadanos puedan relajarse y descansar. De nuevo la potencialidad de los SIG, como tecnología para el diagnóstico y apoyo a las decisiones espaciales, ha sido patente al permitir conocer esas externalidades ambientales que afectan a funciones y entornos altamente sensibles como son las zonas verdes y que deben contribuir a la calidad de vida y bienestar ciudadanos. Aunque parezca muy lejano aún, no debería olvidarse que el horizonte deseable sería disponer de una planificación de los espacios públicos, entre ellos los parques, que garantizase unos paisajes sonoros (soundscapes) armónicos y acordes con las actividades que en ellos se desarrollan, tal como apuntaba Barrett (s.f.) en unas breves disquisiciones.

\section{REFERENCIAS BIBLIOGRÁFICAS}

ALONSO VELASCO, J. M. (1971): Ciudad y espacios verdes. Madrid, Ministerio de la Vivienda, Servicio Central de Publicaciones, $137 \mathrm{pp}$.

AYUNTAMIENTO DE MADRID (1997): Plan General de Ordenación Urbana de Madrid, aprobado por el Pleno del Ayuntamiento de Madrid el 17 de diciembre de 1996. BOCM 92, de 19 de abril de 1997, 6-148.

AYUNTAMIENTO DE MADRID (2002): Mapa de IMD (intensidad media diaria de tráfico rodado) 2002. Concejalía de Gobierno de Seguridad y Servicios a la Comunidad. Publ. en CD-ROM.

AYUNTAMIENTO DE MADRID (2006): Imagen de satélite IKONOS de Madrid. Ayuntamiento de Madrid, Dirección General de Desarrollo y Tecnologías de la Información, SIGMA, Información Cartográfica. Publ. en DVD. 
AYUNTAMIENTO DE MADRID (2011): Ordenanza de Protección contra la Contaminación Acústica y Térmica, aprobada por el Pleno del Ayuntamiento de Madrid el 25 de febrero de 2011. BOAM 6.385, de 7 de marzo de 2011, 5-46.

BARRETT, D. (s.f.): Urban soundscapes: What should a public space sound like? Disponible en web: <http://www.hmmh.com/cmsdocuments/urban_soundscapedeb.pdf $>$.

BRAMBILLA, G. y MAFFEI, L. (2006): Responses to noise in urban parks and in rural quiet areas, Acta Acustica United With Acustica, 92, 881-886.

BRAU, L.; HERCE, M. y TARRAGÓ, M., (1980): Manual municipal de urbanismo. Centre d'Estudis Urbanístics, Municipals i Territorials. Barcelona, CEUMT, vols. 1 y 2.

CANOSA ZAMORA, E.; SÁEZ POMBO, E.; SANABRIA BRASSART, C. y ZAVALA MORENCOS, I. (2003): Metodología para el estudio de los parques urbanos: la Comunidad de Madrid, GeoFocus (Artículos), 3, 160-185. Disponible en web: $<$ http://geofocus.rediris.es/principal.html $>$.

CHIESURA, A. (2004): "The role of urban parks for the sustainable city", Landscape and Urban Planning, 68, 129-138.

COMUNIDAD DE MADRID (1999): Decreto 78/1999, de 27 de mayo, por el que se regula el régimen de protección contra la contaminación acústica de la Comunidad de Madrid. BOCM 134, de 8 de junio de 1999, 13-25 (y corrección del BOCM 154, de 1 de julio de 1999).

ESPAÑA (2003): Ley 37/2003, de 17 de noviembre, del Ruido. BOE 276, de 18 de noviembre de 2003, 40.494-40.505.

INSTITUTO NACIONAL DE ESTADÍSTICA (INE). Nomenclátor [en línea]. Disponible en web: $<\mathrm{http}: / / \mathrm{www}$.ine.es/nomen/nomena.jsp $>$.

KAPLAN, S. (1983): "A model of person-environment compatibility", Environment and Behavior, vol. 15, 3, 311-332.

LAM, K.; NG, S.; HUI, W. y CHAN, P. (2005): Environmental quality of urban parks and open spaces in Hong Kong, Environmental Monitoring and Assessment, $111,55-73$.

LLADÓS GUERRERO, M. (2006): Los espacios públicos en un entorno de SIG, en CAMACHO OLMEDO, M. T.; CAÑETE PÉREZ, J. A. y LARA VALLE, J. J. (2006, eds.): Actas del XII Congreso Nacional de Tecnologías de la Información Geográfica. El acceso a la información espacial y las nuevas tecnologías geográficas. Granada, Universidad de Granada y Grupo de Tecnologías de la Información Geográfica de la Asociación de Geógrafos Españoles, 1.583-1.592. Publicación en soporte CD.

MARTÍNEZ SUÁREZ, P. y MORENO JIMÉNEZ, A. (2005): Análisis espacio temporal con SIG del ruido ambiental urbano en Madrid y sus distritos, GeoFocus (Artículos), 5, 219-249. Disponible en web: $<$ http://geofocus.rediris.es/principal.html $>$.

MARTÍNEZ SUÁREZ, P. y MORENO JIMÉNEZ, A. (2006): El ambiente acústico de los hospitales de Madrid: Metodología de análisis y diagnóstico con S.I.G., en 
CAMACHO OLMEDO, M. T.; CAÑETE PÉREZ, J. A. y LARA VALLE, J. J. (2006, eds.): Actas del XII Congreso Nacional de Tecnologías de la Información Geográfica. El acceso a la información espacial y las nuevas tecnologías geográficas. Granada, Universidad de Granada y Grupo de Tecnologías de la Información Geográfica de la Asociación de Geógrafos Españoles, 995-1.012. Publicación en soporte CD. Disponible en web:

$<$ http://www.ugr.es/ cuadgeo/docs/articulos/039/039-008.pdf $>$.

MARTÍNEZ SUAREZ, P. y MORENO JIMÉNEZ, A. (2009): El ambiente acústico de los parques y zonas verdes de Madrid: metodología para su caracterización, Ponencia de la XII Conferencia Iberoamericana de Sistemas de Información Geográfica. Heredia (Costa Rica), Universidad Nacional de Costa Rica. Disponible en web:

$<$ http://www.geo.una.ac.cr/prosigte/index.php?option=com_remository\&Itemid=1 $69 \&$ func $=$ startdown $\&$ id $=85>$

MORENO JIMÉNEZ, A. (2007): ¿Está equitativamente repartida la contaminación sonora urbana? Una evaluación desde el principio de justicia ambiental en la ciudad de Madrid, Estudios Geográficos, 263, 595-626. Disponible en web: $<\mathrm{http} / /$ estudiosgeograficos.revistas.csic.es/index.php/estudiosgeograficos/article/v iew/70/67>.

MORENO JIMÉNEZ, A. y MARTÍNEZ SUÁREZ, P. (2005): El ruido ambiental urbano en Madrid. Caracterización y evaluación cuantitativa de la población potencialmente afectable, Boletín de la Asociación de Geógrafos Españoles, 40, 153179. Disponible en web: $<$ http://age.ieg.csic.es/boletin/40/07-EL\%20RUIDO.pdf $>$.

PÉREZ MARTOS, J. (2003): Ordenación jurídica del ruido. Madrid, Editorial Montecorvo.

RODRÍGUEZ-AVIAL LLARDENT, L. (1982): Zonas verdes y espacios libres en la ciudad. Madrid, Instituto de Estudios de Administración Local.

SANZ SA, J. M. (1987): El ruido. Madrid, Ministerio de Obras Públicas y Urbanismo, Secretaría General Técnica, Centro de Publicaciones, Serie Unidades Temáticas Ambientales de la Dirección General del Medio Ambiente.

UNIÓN EUROPEA (2002): Directiva 2002/49/CE, del Parlamento Europeo y del Consejo, de 25 de junio de 2002, sobre evaluación y gestión del ruido ambiental. DOCE L 189, de 18 de julio de 2002, 12-25.

ZANNIN, P. H.; FERREIRA, A. M. y SZEREMETTA, B. (2006): Evaluation of noise pollution in urban parks, Environmental Monitoring and Assessment, 118, 423-433. 